\title{
Comprehensive transcriptional analysis reveals salt stress-regulated key pathways, hub genes and time- specific response categories in bermudagrass (Cynodon dactylon) roots
}

An Shao ( $\nabla$ anshao@ldu.edu.cn )

Ludong University https://orcid.org/0000-0002-9398-2001

Wei Wang

Ludong University

Shugao Fan

Ludong University

Xiao Xu

Ludong University

Yanling Yin

Ludong University

Erick Amombo

Ludong University

Xiaoning Li

Ludong University

Guangyang Wang

Ludong University

Hongli Wang

Ludong University

Jinmin Fu

Ludong University

Research article

Keywords: bermudagrass, root, transcriptome analysis, WGCNA, hub genes, time-specific response

Posted Date: July 23rd, 2020

DOI: https://doi.org/10.21203/rs.3.rs-41836/v1

License: (c) (1) This work is licensed under a Creative Commons Attribution 4.0 International License.

Read Full License 
Version of Record: A version of this preprint was published at BMC Plant Biology on April 10th, 2021. See the published version at https://doi.org/10.1186/s12870-021-02939-1. 


\section{Abstract}

Background: Despite the salt-tolerance quality of bermudagrass (Cynodon dactylon), the key pathways and genes involving in salt response and their temporal response pattern have not been deeply identified. Therefore, a comprehensive transcriptome analysis of the bermudagrass roots was conducted in this study to understand the underlying regulatory mechanism following the different period of salt exposure.

Results: The transcripts that commonly and specifically regulated following $1 \mathrm{~h}, 6 \mathrm{~h}$, or $24 \mathrm{~h}$ of hydroponic exposure to $200 \mathrm{mM} \mathrm{NaCl}$ in the roots of bermudagrass were investigated and analysed. The salt-responsive transcripts were mainly divided into 16 distinct temporal expression profiles by analysing the time series dataset. Enrichment analysis identified groups of stress response themes which are consistent or distinctive with generally observed stress response themes, such as hormonal metabolic (e.g. ABA, Auxin, JA, CTK, ethylene), secondary metabolism (e.g. carotenoid, phenylalanine, flavonoid, phenols, glucosinolates), misc (e.g. UDP glucosyl and glucoronyl transferases, oxidases-copper, peroxidases, plastocyanin-like), lipid metabolism (e.g. w-3 FA desaturase), cell wall (e.g. cellulose synthesis MUR4, hemicellulose synthesis, cell wall proteins AGPs), transcription factors (e.g. MYB, HB, AP2, EREBP) and genes encoded a series of transporters (e.g. amino, sugars, nitrate, major intrinsic proteins). Weighted gene co-expression network analysis (WGCNA) revealed that lavenderblush2 and brown4 modules showed significant positive correlations with proline content and peroxidase activity and hub genes within these two modules were further determined. In addition, after $1 \mathrm{~h}$ of salt treatment, categories such as signalling receptor kinase, transcription factors, tetrapyrrole synthesis, lipid metabolism were immediately and specifically up-enriched compared to the following time points, suggesting a fast-acting and immediate physiological responses. Other specific categories involved in secondary metabolite biosynthesis such as simple phenols, glucosinolates, isoflavones and tocopherol biosynthesis were specifically up-regulated after $24 \mathrm{~h}$ salt treatment, suggesting longer-term reactions of metabolic adjustment.

Conclusion: This study revealed salt response themes that were commonly or differentially expressed in earlier or later salt exposure phases, suggesting adaptive salt response mechanisms in the roots of bermudagrass. In addition, the distinctive salt-response pathways and potential salt-tolerant hub genes investigated can provide useful references to study the salt response of bermudagrass in the future.

\section{Background}

Soil salinity is one of the most significant abiotic stresses affecting plant growth and development. Plants have evolved a series of physiological and molecular response mechanisms to mitigate the osmotic stress, ion toxicity and oxidative damage caused by salt stress [1-5]. Bermudagrass (Cynodon dactylon) is one of the most popularly-utilized warm-season turf species which can spread by stolons, rhizomes, and seed [6, 7]. It is also considered to have strong salt tolerance, but there are differences among varieties. The growth and development of most varieties could be seriously inhibited by salinity stress, greatly limiting its promotion and application in saline soils $[8,9]$. Therefore, depth analysing the 
salt tolerance mechanism and mining key response genes and pathways will contribute to its application in saline environments.

Salt stress always leads to a genome-wide transcriptomic reprogramming in plants. Groups of genes related to many physiological traits and salt-response pathways are regulated to alleviate the adverse effects, making salt response into a complex quantitative trait $[1,2,10]$. Immediately after plants perceive salt stress from the surrounding environment, they could rapidly activate multiple signal transduction pathways $[11,12]$ and the elevated concentration of calcium ion $\left(\mathrm{Ca}^{2+}\right)$ is among the first response to external stimuli [13]. Following sensing by their sensors (e.g., CBLs: calcineurin B-like proteins; CIPKs: $\mathrm{Ca}^{2+}$-independent protein kinases; CDPKs: $\mathrm{Ca}^{2+}$-dependent protein kinases; CMLs: calmodulin-like proteins) [1, 13], a series of reactions, such as the salt overly-sensitive (SOS) and mitogen-activated protein kinase (MAPK) pathways are triggered to cope with the stimuli [14-17]. In the meanwhile, linked to $\mathrm{Ca}^{2+}$ signalling, other second messengers such as reactive oxygen species (ROS) are also induced [5]. Although ROS can function as signalling molecules in response to environmental challenges [3, 18], high levels of ROS can result in cell oxidative damage [19]. Therefore, a complex scavenging system consisting of antioxidants enzyme (e.g. catalase, CAT; peroxidase, POD; superoxide dismutase, SOD) and non-enzymatic scavengers (e.g. tocopherols; carotenoids; phenols) have been developed to scavenge ROS and protect themselves $[20,21]$. In addition, the phytohormones-mediated signalling pathways (e.g. auxin; abscisic acid, ABA; jasmonic acid, JA; cytokinin, CTK; gibberellin, GA; ethylene, ETH) also play key roles in the adaptive growth of plants after environmental stimulation [22-24].

These activated cascades such as $\mathrm{Ca}^{2+}$, ROS, and hormone signaling cascades can further activate other regulators downstream such as transcription factors (e.g. ABA-responsive element-binding protein/ABAbinding factor, $A B R E / A B F$ ) to further initiate the induction or repression of functional genes within the protective mechanisms [25]. For example, to cope with the initial osmotic stress induced by salt stress, genes regulating levels of osmoprotectants are reported to be the first stress-inducible transcripts. The intracellular concentrations of osmolytes such as proline, soluble sugar and dehydrins are increased to improve the osmotic adjustment of cell $[3,26]$. After longer salt treatment, other strategies will be applied to alleviate $\mathrm{Na}^{+}$toxicity, for example, the ion transporters such as HKT (high-affinity $\mathrm{K}^{+}$transporter) and $\mathrm{NHX}\left(\mathrm{Na}^{+} / \mathrm{H}^{+}\right.$antipoters) gene families could be regulated to further sequester or compartmentalize excess $\mathrm{Na}^{+}$in the vacuole to maintain a high cytosolic $\mathrm{K}^{+} / \mathrm{Na}^{+}$ratio and resist to salt stress $[27,28]$.

When plants are exposed to stress in the form of excess salt, roots are the first site at which salinity is detected and are more sensitive to salt stress compared to shoots $[29,30]$. Salt treatment always leads to an early-onset osmotic response in roots, which subsequently affects the whole plant [3]. Therefore, roots provide a sensitive target to study the molecular mechanisms underlying plant salt tolerance and adaptation [31]. Several transcriptomic studies in the roots have been done on salt stress with different species [32-34]. Recently, transcriptome analysis in the roots of bermudagrass was performed after seven days of salt stress using two varieties differed in salt tolerance [35]. However, transcriptomic researches in the roots of bermudagrass that involve in multi-time points have not been done yet. When evaluating a 
plant's response to a stress factor, these temporal dynamic changes taken into consideration could provide a more systematic analysis in the expression profiles [29, 36, 37]. In this study, a comprehensive transcriptome analysis of the bermudagrass roots exposed to salt stress for $1 \mathrm{~h}, 6 \mathrm{~h}$ and $24 \mathrm{~h}$ were conducted to investigate the common and specific response patterns and expression connections of salt response genes. Some key regulatory pathways, gene families and hub genes were identified. These results could give an overview of the early-salt response transcription map and provide more useful information for further study of the salt response of bermudagrass.

\section{Results}

\section{Effect of salt stress on physiological parameters of bermudagrass roots}

To study the early response to the salt stress in the roots of bermudagrass, the seedlings were treated with $200 \mathrm{mM} \mathrm{NaCl}$ for $1 \mathrm{~h}, 6 \mathrm{~h}$ and $24 \mathrm{~h}$ respectively and the roots samples were collected for physiological parameters determination and transcriptome analysis. Because the treatment time exposed to salt is relatively short, the growth parameters such as plant height shoot biomass and root length were not significantly affected (data not shown). However, the roots of $24 \mathrm{~h}$ salt-treated plants displayed higher malondialdehyde (MDA) content than control plants (Fig. 1a). The POD activity was significantly higher in the roots of $1 \mathrm{~h}$ and $6 \mathrm{~h}$ salt-treated seedlings compared to that in their respective control roots

(Fig. 1b). The SOD activity of $1 \mathrm{~h}$ and $6 \mathrm{~h}$ salt-treated roots showed an upward trend, but the increase was not significant compared to their respective control plants (Fig. 1c). In addition, the salt treatment significantly induced the proline accumulation of roots compared to non-salinity conditions. (Fig. 1d). The accumulation of these metabolites indicated that the roots of plants were experiencing salt stress and producing a stress response at the time when subjected to transcriptome analysis.

\section{General transcriptomic responses in the roots of bermudagrass}

Samples of roots of bermudagrass were collected from both $200 \mathrm{mM} \mathrm{NaCl}$ treated plants (Salt $1 \mathrm{~h}$ _R; Salt 6 h_R; Salt 24h_R) and untreated plants (CK 1 h_R; CK 6 h_R; CK 24 h_R) after 1 h, 6 h and 24 h respectively. Each treatment comprised three replications and 18 sequencing libraries were prepared to study the response of roots to salt-stress during early stage at the transcriptome level. Clean reads are de novo assembled by Trinity to get assembly transcriptome. Then Corset will perform Hierarchical Clustering to remove redundancy. Totally 695542 transcripts and 694799 unigenes with an N50 of 1391 bp were obtained. More than $97 \%$ had Phred-like quality scores at the Q20 level (an error probability of $1 \%$ ) among all the clean reads and approximately $74 \%$ of the total clean reads were mapped to the reference transcriptome. Gene expression profiles of the control and $\mathrm{NaCl}$-treated samples were compared and analysed to identify the differentially expressed genes (DEGs) using the cuffdiff program. Stringent values of $\log _{2}$ fold change $\geq 1$ or $\leq-1$ and false discovery rate (FDR) $\leq 0.05$ and FPKM value $\geq 1$ in at least one of the samples were used as thresholds to assess the significance of differential gene expression. The results showed that the expression of 58979 genes was significantly altered in response to salt stress at one or more time points. The Venn diagram indicated that 229 genes were up-regulated 
and 764 genes were down-regulated at all three time points (Fig. 2a, b). Among the up-regulated genes after salt stress, 3812 genes were specific to $1 \mathrm{~h}$ and 2670 genes were specific to $6 \mathrm{~h}$ whereas 1258 genes were specific for $24 \mathrm{~h}$ (Fig. 2a). Among the down-regulated genes, the expression of 31409 genes was modulated specifically at $1 \mathrm{~h}$, the expression of 6538 genes was modulated only at $6 \mathrm{~h}$ whereas the expression of 3054 genes was specific for $24 \mathrm{~h}$ (Fig. 2b; Table S1). On the overall level, a majority of the responsive genes were down-regulated by $\mathrm{NaCl}$ at three time points, respectively (Fig. 2c). In addition, the number of differential expression genes after $1 \mathrm{~h}$ salt treatment was relatively more than the number after $6 \mathrm{~h}$ and $24 \mathrm{~h}$ salt treated (Fig. 2c, d).

\section{Expression profiles of different expression genes}

We further detected the expression patterns of DEGs whose treated (S): untreated (CK) $\log _{2}$ expression ratio differed significantly from 0 at one or more time points using the STEM (Short Time-series Expression Miner) software package (Table S2) and 16 distinct temporal expression patterns were determined (Fig. 3). The predominant profiles indicated that the expression of majority DEGs changed rapidly within the first $1 \mathrm{~h}$ following salt treatment (Fig. 3). Some genes had a peak response (repression or induction) at $1 \mathrm{~h}$ (Fig. 3e, i, o) and other group of genes reached a peak change at $6 \mathrm{~h}$ (Fig. $3 \mathrm{~d}, \mathrm{~g}$ ) or 24 $\mathrm{h}$ respectively ( $\mathrm{Fig} 3 \mathrm{~b}, \mathrm{j}, \mathrm{l}, \mathrm{m}, \mathrm{p}$ ). Some genes responded at $1 \mathrm{~h}$ continued along the same trajectory at the following time points (Fig. 3b, m) or returned towards untreated levels (Fig. 3i, o). The response of some genes showed an induction at $1 \mathrm{~h}$ and maintained similar levels of induction observed at $1 \mathrm{~h} \mathrm{(Fig.} \mathrm{3e,} \mathrm{f).}$ The response of some genes showed a relatively little response until $24 \mathrm{~h}$ (Fig. 2l, p). Some genes showed the opposite patterns of induction and repression at $6 \mathrm{~h}$ as compared to $1 \mathrm{~h}$ or $24 \mathrm{~h}$ (Fig. 3c, n). Some genes showed a moderate response at $1 \mathrm{~h}$ and $6 \mathrm{~h}$ and showed a slightly response at $24 \mathrm{~h}$ (Fig. 3h, k). Still other genes that were repressed at $1 \mathrm{~h}$ showed a slightly repression at $6 \mathrm{~h}$ and a renewed intensity of repression at $24 \mathrm{~h}$ (Fig. 3a). Thus, although the majority of genes were responsive by $1 \mathrm{~h}$ of salt treatment, dynamic patterns of gene expression profiles were also detected. These expression profiles indicated that there might be a time-specific response pattern in the roots of bermudagrass.

\section{Functional categorization and pathway analysis of differentially expressed genes}

To understand the salt response categories and detect the commonly and differently response between different time points, further analysis were conducted. PageMan analysis was then used to analyse the relationship between response time points of transcripts and their biology meanings. Analysis of these DEGs using PageMan system showed that bins involved in major metabolism (2), cell wall (10), secondary metabolism (16), hormone metabolism (17), stress (20), misc (26), development (bin 33) and transport (34) were all up-enriched (Fig.4a-f; Table S3) whereas the DNA (28), protein (29), energy-related (8: TCA/org transformation; 9: mitochondrial electron transport/ATP synthesis) and cell (31) related bins showed significant depletion of up-regulated genes under salt stress at all three time points (Fig. S1; Table S4). These consistently and continuously up-regulated categories mainly included genes participated in ABA synthesis and signaling transduction (e.g. 9-cis-epoxycarotenoid dioxygenase, NCED; protein phosphatase $2 \mathrm{C}, \mathrm{PP} 2 \mathrm{C}$; ABRE binding factors, ABFs) (Fig.5a), transcription factors (e.g. members 
of HB, MYB and bZip) (Fig.5b), several groups of transporters (Fig. 5d) (e.g. transporters of sugars, amino acids, peptides and oligopeptides; $A B C$ transporters; multidrug resistance systems; major intrinsic proteins.PIP), genes regulating levels of osmoprotectants (e.g. S-adenosylmethionine decarboxylase; galactinol synthases; raffinose sythases; trehalose; callose; galactose), transcripts that encode antioxidant enzymes (e.g. peroxidase), genes participated in oxidases stress, such as oxidases-copper, glutathione $S$ transferases, beta 1,3 glucan hydrolases, plastocyanin-like proteins) and other proteins (e.g. the late embryogenesis abundant proteins and AWPM-19-like membrane family proteins participated in osmotic stress response; genes participated in phenylpropanoids, carotenoids, flavonoids and polyamine metabolism such as 4-coumarate-CoA ligase 1 (4CL-like), peroxidase 1, phytoene synthase gene ( $P S Y 3$ ) and 2-oxoglutarate (2OG) and Fe(II)-dependent oxygenase superfamily protein) (Fig. S2a; Table S1). Although the protein synthesis and amino acid activation sub bins showed significant depletion of upregulated genes under all three time points, the protein modification sub-bin showed significant enrichment of up-regulated genes (e.g. members of PP2C, HAB, HAI, WIN, CIPK family) (Fig. 5c). However, genes involved in protein translational modification such as kinase and ubiquitination pathway-related genes were up-regulated (Fig. S3).

\section{Salt response categories at different time points}

Following salt treatment, some categories showed salt specifically response at different time points (Table S3). The receptor-like kinase sub-bin (30.2) involved in signaling bin (30) was specifically overrepresented immediately after exposed to salt for $1 \mathrm{~h}$ (Table S3; Fig. S4a), including receptors such as leucine-rich repeat (LRR V, VIII and XII), thaumatin-like, Catharanthus roseus-like RLK1, domain of unknown function (DUF) 26, legume-lectin domain (LLD), LRK10 like; lysine motif, proline extension-like (PERK), S-locus glycoprotein like and wall-associated receptor kinase (WAK). Some gene members involved in calcium signaling were specifically up-regulated immediately after the roots were exposed to salt for $1 \mathrm{~h}$ (e.g. calcium-dependent protein kinase, CDPK11; Calmodulin, CAM3; calmodulin-domain protein kinase, CPK5; calmodulin-like, CML43). A mitogen-activated protein kinase MAPK2 (cluster342212.26954), which is homolog to At2g43790 was also up-regulated specifically at $1 \mathrm{~h}$ (Fig.S2b). Sub bins involved in hormone metabolism (17) such as JA synthesis-degradation (17.7.1) and signal transduction (17.7.2), CTK metabolism (17.4) and ETH metabolism (17.5) were specifically induced at $1 \mathrm{~h}$ (Table S3; Fig. 4a). Genes participated in ETH biosynthesis (one ACC synthase and four ACC oxidase), ethylene signal transduction (three ERF and one DREB), JA biosynthesis (one allene oxide synthase, AOS1; one allene oxide cyclase, AOC4), JA signal transduction (JAZ1) and CTK metabolism degradation (five UDP-glucosyl transferase and nine cytokinin oxidase) were significantly up-regulated under $1 \mathrm{~h}$ salt treatment, indicating that these hormones participated in the early response to salt stress in the roots of bermudagrass (Table S3, Fig. 4a). In addition, a series of transcription factors sub bins (e.g. ARF: 27.3.4; ARR: 27.3.12; C3H: 27.3.5; NAC: 27.3.27; Trihelix: 27.3.30; AS2: 27.3.37; JUMONJI: 27.3.57; PHOR1: 27.3.64; Psudo ARR: 27.3.68) showed over-represented after $1 \mathrm{~h}$ salt treatment compared to the later time points, implying that these TFs might be specifically involved in early salt response in the roots of bermudagrass (Table S5; Fig. S5). There are also some other genes specially response at $1 \mathrm{~h}$, including several groups of transporters (e.g. major intrinsic proteins NIP, PIP); stress response molecules (e.g. 
typsin inhibitor, PR proteins, MLO-like receptors), lipid metabolism (e.g. choline kinase) (Table S3). More map-bins were found specifically over-represented after seedlings were exposed to salt for $1 \mathrm{~h}$ compared to the latter two time points (16 at $1 \mathrm{~h}, 10$ at $6 \mathrm{~h}$ and 11 at $24 \mathrm{~h}$ respectively) (Fig. S6), such as bins of tetrapyrrole synthesis (19), biodegradation of xenobiotics (24), lipid metabolism (11), suggesting an earlier response of salt (Fig. S4). However, the polyamine synthesis sub-bin showed over-represented only after $6 \mathrm{~h}$ and $24 \mathrm{~h}$ salt treatment (Fig. S6). In the secondary metabolism bin, the sub bin related to isoprenoid, phenylpropanoid and flavonoids metabolism were presented upregulated at all three time points when exposed to salt. However, some sub-bins included in secondary metabolism (16) were specifically over-represented at $24 \mathrm{~h}$ (Fig. 4b; Fig. S7), such as simple phenol (16.10), glucosinolates (16.5.1), isoflavones (16.8.5) and tocopherol biosynthesis (16.1.3) (Table S3), indicating a slightly delayed response of salt. These results revealed that regulators or effectors involved in different saltresponse categories might be active at different periods following the perception of salt stress.

\section{Coexpression network analysis and hub gene investigating by WGCNA}

To identify the specific genes that are highly associated with salt response in the roots of bermudagrass, WGCNA was further performed (Table. S7). Further analysis identified 13 network modules in the coexpression network based on pairwise correlations of gene expression across all samples, designated Turquoise, Black, Brown, Pink, Magenta, Red, Green, Blue, Yellow, and Grey (Fig. 6a, c). Investigating the relationships between module eigengene and salt response physiological indexes (proline/POD/SOD) uncovered that the correlation coefficients varied widely from -0.67 to 0.70 in proline, from -0.55 to 0.70 in POD and from -0.55 to 0.70 in SOD (Fig. 6c). We selected trait-specific modules at the $p$ value $<0.05$ level. Four modules were associated with proline content, five modules with POD and two modules with SOD. The eigengenes of two modules lavenderblush2 and brown4 showed significant positive correlations $(p<0.001)$ with proline and POD, suggesting these modules had greater relevance in salt response (Fig. $6 \mathrm{c}$ ). Further, the lavenderblush2 and brown 4 modules, representing 882 and 438 genes respectively were visualised with the Cytoscape software (Table. S8). The top three hub genes of brown4 co-expression network contained one homologues of hypothetical protein MTR_3g035650 from Medicago truncatula (Cluster-342212.125010), one hypothetical mitochondrion protein homolog to AGC78945.1 from Vicia faba (Cluster-342212.139315) and one classical transcription factor HSF(cluster-342212.125010) (Figure 6a; Table S7). The top three hub genes of co-expression network lavenderblush2 contained one gene encoding $\beta$-amylase (Cluster-342212.182369), which is belonged to glycosyl hydrolase family 14 . However, the other hub genes of these two modules were genes not clearly annotated (Table S7). Whether these hub genes really function in salt response in the roots of bermudagrass should be the subject of further research.

\section{qRT-PCR validation of selected deferentially expressed genes}

To validate the RNA-seq data, the expression level of eight hub genes with different expression pattern (Fig.7) from two WGCNA modules were further determined by qRT-PCR analysis (Fig. S8; Table. S9). The expression patterns verified by qRT-PCR and the FPKM values of these genes showed similar trend under 
the corresponding treatments. The expression profiles of all three hub genes from the module lavenderblush 2 showed an induced expression after $1 \mathrm{~h}$ salt stress but a decreased expression or no obvious alteration at the latter time points (Fig. 7a-c; Fig S8a-c). The expression of hub genes from the module brown4 showed a significant induction at all three time points when the roots were exposed to salt (Fig. 7d-h; S9d-h). These results not only confirmed that the RNA-seq data were reliable but also revealed their differential response pattern of these hub genes.

\section{Discussion}

\section{Time-specific quick salt response modules in the roots of bermudagrass}

Previous transcriptome analysis of plants under salt stress reveals differential response at early and late stages of stress [36,37]. The temporal dynamic gene expression changes could give us a more comprehensive analysis to evaluate a plant's response to a stress factor. Through comprehensive transcriptional analysis of the salt-responsive DEGs in the roots of bermudagrass which were exposed to salt for multi-time points, our results provided a list of key response genes and categories showing dynamic expression change pattern. Generally, compared with their respective control roots, 44,847 (4760 up- and 40,087 down-regulated), 18,793 (3730 up- and 15,063 down-regulated), 7362 (1915 up- and 5447 down-regulated) DEGs were specifically regulated in $1 \mathrm{~h}, 6 \mathrm{~h}$ or $24 \mathrm{~h}$ salt-treated bermudagrass, respectively (Fig. 2c). The diversity of temporal expression patterns of DEGs further detected by STEM also indicated a time-specific response and a highly complex regulatory network underlying the response to salt stress in the roots (Fig. 3). These data also showed that about 2.4 and 6 times more specific saltresponsive genes were differentially regulated in the roots exposed to salt for $1 \mathrm{~h}$ than those exposed to salt for $6 \mathrm{~h}$ or $24 \mathrm{~h}$ respectively, suggesting that more genes showed a quick response when subjected to salt (Fig. 3). As a consequence, more salt response categories were enriched at $1 \mathrm{~h}$ compared to later time points (Fig. S6; Table S3).

For example, after perceiving abiotic stimuli, signal receptors kinases always response at earlier time point to function in protein phosphorylation and modification, which is an important mechanism in initiating salt response signalling pathways and leading to transcription regulation [38-42]. In the roots of bermudagrass, several signal receptors like kinases (e.g. LRR, thaumatin-like, RLK1, DUF26, LLD, LRK10 like, PERK, WAK) were found immediately and specifically up-regulated at $1 \mathrm{~h}$ compared to the latter time points (Fig. S4a). Moreover, the salt signal could also immediately trigger the downstream hormones pathways, which are known to be involved stress responses in a wide range $[22,23,24,60]$. In this study, genes involved in ABA synthesis and signal transduction sub-bins (17.1.1, 17.1.2, 17.1.3) showed consistently up-enriched at all three time points (e.g. NCED, PP2C, ABFs) (Fig.5a), suggesting the established role to salt response $[23,24]$. However, we also noticed that transcripts involved in the metabolism of biosynthesis and signal transduction of ETH and JA were specifically over-represented when the roots were exposed to salt for $1 \mathrm{~h}$ (Fig. 4a; Table S3), indicating that these salt responsive hormones metabolism pathways might participate in the quick response to salt stress in the roots of bermudagrass $[37,43,44]$. In addition, the induced of transcripts involved in CTK and GA degradation 
were noticed (Fig. 4a; Table S3). Transcripts encoding gibberellin-degrading enzyme gibberellin 2-oxidase (homologs of At4g21200 and At1g75450 respectively) suggested the cell growth were partly inhibited to survive under salt stress. The expression of at least 9 transcripts of AtCKX6 (At1g75450) homologs showed up-regulated (Table S3), which encoding a cytokinin oxidase/dehydrogenase participated in catalysing the degradation of cytokines [45-46]. These results suggested that hormone signaling does not work alone while mediating salt response and might function in multifarious crosstalk network with other hormones.

Intracellular phosphorylation events are downstream of secondary messengers ( $\mathrm{Ca}^{2+}, \mathrm{ROS}$ or hormones), such as CDPKs [11-17] and MAPK cascades [47-49], which are reported to be essential sensortransducers in plants. In this study, some gene members involved in calcium signaling also showed a quick response immediately after the roots were exposed to salt for $1 \mathrm{~h}$ (e.g. CDPK11, CAM3, CPK5, CML43) (Fig. S4a; Table S3). Some calcium-transporting ATPase encoding genes were specifically overrepresented at $1 \mathrm{~h}$, which could further promote the transmembrane transport of $\mathrm{Ca}^{2+}$ (Table S3). A mitogen-activated protein kinase MAPK2 (cluster-342212.26954), which is a homolog to At2g43790 was also up-regulated specifically at $1 \mathrm{~h}$ (Fig. S2b), might interplay with ROS and hormone in salt response $[50,51]$. The immediately up-regulation of these protein kinases encoding genes might further trigger downstream transcriptome reconfiguration to cope with the stressful salt condition [52].

In this study, we also identified more than ten transcription factor families, which were significantly induced at one or more time points after the roots were exposed to salt condition (Fig. S5) and the induced TFs number was much more at $1 \mathrm{~h}$ than that at latter time points. Among those TFs, AP2, WRKY, bHLH and HB families accounted for a large ratio of the total number of salt induced TFs identified and three families (MYB, HB, bZip) were significantly induced at all three time points (Fig. 5b; Table S5). Through WGCNA, one HSF transcription factor was investigated as hub gene. This HSF transcription factor showing up-regulated by salt at all three time points could be a good target to study in the future (Fig. 7f). Consistent with the previous studies that WRKY TFs could positively or negatively participate in salt tolerance [50-59], we observed that transcripts for 20 of the 23 WRKY TFs detected significantly induced in response to $1 \mathrm{~h}$ salt treatment in the roots of bermudagrass (Fig. S5; Table S5). The AP2/EREBP family were reported to include some stress responsive transcription factors [61, 62]. In this study, we also observed 16 of 17 AP2 transcripts were up-regulated after $1 \mathrm{~h}$ salt treatment. When exposed to salt, another most affected TF family in the roots of bermudagrass was bHLH, with 24 of 28 transcripts were induced at $1 \mathrm{~h}$ and 10 of 19 were increased at $6 \mathrm{~h}$ by salt stress (Table S5). Among these induced bHLH transcription factors, some important members which have been reported positively participated in salt stress response such as bHLH92 [63]. The Aux/IAA families were significantly enriched in salt-responsive transcripts especially at $1 \mathrm{~h}$ with all 12 transcripts all up-regulated by salt stress (e.g. IAA5, 12, 20, 24, 18, 23) (Table S5). These salt response Aux/IAA genes have a central role in auxin response and might act to integrate environmental inputs into the auxin gene regulatory network [64]. In addition, a series of transcription factors (e.g. ARF, ARR, C3H, NAC, Trihelix, AS2, JUMONJI, PHOR1, Psudo ARR) showed specifically up-enriched under $1 \mathrm{~h}$ salt treatment compared to the later time 
points, implying that these TFs might be specifically involved in quick salt response in the roots of bermudagrass (Fig. S5; Table S5). Therefore, in this study, we noticed that some molecular processes, such as signal transduction, hormone metabolism and regulation of transcription factors were induced at earlier time point and might form a cascade to active the downstream response factors.

\section{Common and distinctive positive salt response mechanisms in the roots of bermudagrass}

It is well known that plants have evolved large gene families for detoxification of ROS caused by harsh environments such as salt $[20,21,64,65]$. In our study, the POD activity was significantly higher in the roots of $1 \mathrm{~h}$ and $6 \mathrm{~h}$ salt-treated seedlings compared to that in their respective control roots (Fig. $1 \mathrm{~b}$ ) and a few members of POD encoding genes were up-regulated (Fig. 4d; Table S3). Other members of gene families encoding oxidases-copper, glutathione $S$ transferases, beta 1,3 glucan hydrolases, UDP glucosyl and glucoronyl transferases, plastocyanin-like proteins (Fig. 4d; Table S3) also showed up-regulated at one or more time points to cope with the salt stress. For example, UDP glucosyl transferases UGT79B2/B3 in Arabidopsis was reported to contribute to cold, salt and drought stress tolerance via modulating anthocyanin accumulation and enhancing ROS scavenging [66]. Consistent with the previous studies, some bioactive secondary metabolities in the roots of bermudagrass (e.g. carotenoids, tocopherols and flavonoids) [67-69] were also over-represented under salt and might also serve as ROS scavengers (Fig. 4b; Table S3). As expected, genes regulating levels of osmoprotectants also showed highly stress responsive in salt-treated roots of bermudagrass, such as genes encoding galactinol synthases, raffinose synthase, trehalose, callose and galactose (Fig. S4d), which were reported to be the first stress-inducible genes under salt stress [28-31].

The plant cell wall is considered an important factor involved in sensing of and response to salt stress, which mainly consists of cellulose, hemicellulose, lignin, pectins and many glycoproteins [70, 71]. In this study, we also noticed that genes involved in cellulose synthase (10.2), hemicellulose synthesis (10.3) and lignin synthesis (16.2.1) were over-represented in the salt-treated roots of bermudagrass (Fig. 4f). The expression of glycoside hydrolase $\mathrm{GH} 17$ family genes was significantly induced when exposed to salt for $1 \mathrm{~h}$ (Fig. 4d; Table S3), which might be participated in the post-translational modifications of cell wall proteins and lead to the alteration of cell wall flexibility [72-75]. In addition, a limited number of other cell-wall related gene families which function in cell wall extensibility were also showed differential regulation in salt responsive transcripts of bermuagrass. For example, the expression of MUR4 was found up-regulated in the roots of bermudagrass (Fig. 4f), which was reported to be involved in the biosynthesis of UDP-arabinose. Mutation in MUR4 affects cell wall integrity and leads to reduced root elongation and defective cell-cell adhesion under high salinity [76]. Moreover, a number of AGPs (arabinogalactan proteins) encoding genes were found up-regulated by salt at the transcript level in our study (Fig.4f). The AGPs on cell walls or plasma membranes are also reported to be associated with cell growth $[77,78]$ and one AGP (SOS5) was known to contribute to salt tolerance in Arabdiopsis [79]. We further noticed that the lipid metabolism showed a quick response in the roots of bermudagrass. The expression of genes involved in FA synthesis and elongation were down-regulated while genes involved in FA desaturation and lipid degradation were significantly up-regulated immediately when exposed to salt for $1 \mathrm{~h}$ (Fig. S4b). 
Studies have shown that FA desaturases play an important role in the maintenance of the biological function of membranes in plant cells under different conditions including salt stress [80-82]. In our study, salt stress markedly changed the expression of genes encoding $\omega-3$ FA desaturases and might lead to an alteration of FA composition (Fig. S4b, Table S3). The immediately regulated expression of genes coding for recombination of lipid composition can provide novel insights for the improvement of salt tolerance in bermudagrass.

Except for secondary metabolisms related genes which significantly participated in cell wall modification (Fig. 4f), some important secondary metabolism pathways were significantly induced in the later phase, suggesting longer-term reactions that may involve metabolic adjustment [83, 84]. For example, the polyamine synthesis sub-bin showed over-represented only after $6 \mathrm{~h}$ and $24 \mathrm{~h}$ salt treatment. Some subbins included in secondary metabolism were specifically over-represented at $24 \mathrm{~h}$, such as simple phenol, glucosinolates, isoflavones and tocopherol biosynthesis (Fig. 4b; Table S3). These secondary metabolisms were previously reported to be involved in plants oxidative response in some species [83, 84]. For example, the expression of laccase encoding genes was found up-regulated especially when exposed to salt for $24 \mathrm{~h}$, which might participate in the oxidation and reduction of simple phenols in the roots of bermudagrass and alleviate the oxidise stress caused by salt stress [85-87].

\section{Categories downregulated by salt stress in the roots of bermudagrass}

In previous proteomic studies, protein translation always showed a decrease following $\mathrm{NaCl}$ treatment, which is consistent with this study that the majority of transcripts for almost all ribosomal proteins were down-regulated (Fig. S3; Table S3) [31, 88]. The inhibited protein synthesis and enhanced protein degradation might increase the concentration of free amino acid, especially proline. Proline can be used as osmotic protective substance under osmotic stress and free amino acid could further used for the synthesis of dehydrin or polyamine, which might function in the maintenance of the structure of protein and cell membrane under salt. However, genes involved in protein translational modification such as kinase and ubiquitination pathway related genes were up-regulated (Fig. S3). Notably, E3 RING and E3 SCF proteins were significantly enriched in salt induced genes (Fig. S3; Table S3), suggesting that these enzymes function in ways that might be independent of the $26 \mathrm{~S}$ proteasome in salt response $[89,90]$. Moreover, genes required for the tricarboxylic acid cycle (TCA), which is the main respiratory pathway were generally down-regulated by salt stress (Fig. S1a; Table S3). For example, genes encoding pyruvate dehydrogenases, which function in the conversion of pyruvate to acetyl-CoA and thereby links the glycolytic pathway to the TCA cycle, were enriched among down-regulated profiles (Fig. S1a; Table S3). Genes encoding components of the mitochondrial elecron transport chain such as NAD $(P) H$ dehydrogenases and F1-ATPase were also especially enriched among down-regulated profiles (Fig. S1b; Table S3), suggesting that the mitochondria might be damaged by oxidative stress. In addition, we also noticed that genes involved in DNA synthesis and cell organization also showed down-regulated (Fig. S1c, d). These down-regulation pathways might function together in conserving energy to maintain plants growth and development[31, 91]. 


\section{Conclusions}

A comprehensive transcriptome analysis of the bermudagrass roots was conducted to understand the underlying regulatory mechanism following salt exposure. We identified groups of stress response themes which are consistent or distinctive with generally observed stress response themes. In addition, categories such as signaling receptor kinase, transcription factors, lipid metabolism response to salt at earlier time point while other categories involved in secondary metabolite biosynthesis response at latter time point. These time-specific response might reveal that regulators or effectors involved in different salt-response categories might be active and function at different periods after salt stress. In addition, the distinctive salt-response pathways and potential hub genes investigated in this study can provide useful references to further study the salt response mechanism of bermudagrass in depth.

\section{Methods}

\section{Plant materials and growth conditions}

The uniform stolons of bermudagrass were planted in solid in one month, and the seedlings mowed to the same height were transferred into $\mathrm{CK}(0 \mathrm{mM} \mathrm{NaCl})$ and salt stress $(100 \mathrm{mM} \mathrm{NaCl})$ conditions in a hydroponic culture. The hydroponic culture was processed in a growth chamber under the following conditions: $22 / 18^{\circ} \mathrm{C}$ (day/night), $65 \%$ relative humidity, $300 \mu \mathrm{mol} \mathrm{m} \mathrm{m}^{-2} \mathrm{~s}^{-1}$ photons and a 16 -h day/8-h night cycle. The culture solution was refreshed every two days.

\section{Transcriptome analysis}

The root samples of $1 \mathrm{~h}, 6 \mathrm{~h}, 24 \mathrm{~h} \mathrm{NaCl}$ treated seedlings (Salt $1 \mathrm{~h} \_\mathrm{R}$; Salt $6 \mathrm{~h} \_\mathrm{R}$; Salt 24h_R) and their respective control plants (CK 1 h_R; CK 6 h_R; CK 24 h_R) were used for transcriptome analysis. Each treatment comprised three replications and 18 sequencing libraries were prepared for RNA sequencing on Illumina HiSeq 2000. RNA extraction was conducted following the Spectrum Plant RNA extraction kit (Sigma-Aldrich, USA) and total RNA quality was assessed. The high quality RNA samples were used for library preparation. The aligned reads were used for estimating the expression of the genes and transcripts using the cufflinks program (version 2.0.2) and the transcripts expression distribution was estimated in FPKM (Fragments per kilobase per million mapped reads). The differential expression analysis was performed using the cuffdiff program (version 2.0.2). MapMan were used for pathway analysis and identification of significantly affected pathways [92].

\section{Gene expression pattern analysis by STEM}

For temporal expression profiles analysis, STEM software were used [93]. DEGs whose treated (S): untreated (CK) $\log _{2}$ expression ratio differed significantly from 0 at one or more time points were used. The maximum number of model profiles set to 16 , and maximum unit change set to 3 .

\section{WGCNA}


Enrichment analyses of the WGCNA modules were all conducted by hypergeometric tests using POD, SOD, CAT, MDA and proline content against the same background of expressed genes [94]. The cutoff for significant enrichment is PFDR<0.05.

\section{Quantitative RT-PCR Analysis}

For realtime PCR, RNA was extracted from the roots of three biological replicates at all the time points. Total RNA was isolated and reverse transcribed using the RNeasy kit (Qiagen) and TaqMan reverse transcription kit (Applied Biosystems). Quantitative real-time RT-PCR analysis was conducted using SYBR Green real-time PCR master mix (Toyobo, Japan) and ABI real-time PCR system (Applied Biosystems, FosterCity, CA). The primers used are listed in Table S8. The Actin2 gene of bermudagrass was used as an inner control, and comparative Ct method was applied for analysis.

\section{Statistical Analysis}

One-way ANOVA was performed using SPSS17.0 for Windows (SPSS). All of above tests had at least three independent replicates. Results were expressed as mean $\pm S D$, and * show significant differences ( $P$ $<0.05$ ) by Student's $t$-test.

\section{Abbreviations}

ABC: ATP-binding cassette; $A B I$ : ABA insensitive; $A O C$ : allene oxide cyclase; AOS: allene oxide synthase; AP2: Apetala-2; ARF: Auxin response factor; bHLH: basic helix-loop-helix; bZIP: basic leucine zipper; CAM: Calmodulin; CDPK: calcium-dependent protein kinase; CAT: Catalase; CML: calmodulin like; CPK: calmodulin-domain protein kinase; COMT: Caffeic acid O-methyltransferase-like; DEGs: differentially expressed genes; EREBP: ethylene response element binding protein; ERF: ethylene response factor; FDR: false discovery rate; GH: glycoside hydrolases; GST: Glutathione S-transferase; GT: Glycosyltransferases; HB: homeobox; HKT: High-affinity $\mathrm{K}^{+}$transporter; HSF: Heat shock factor; LLD: legume-lectin domain; MAPK: mitogen-activated protein kinase; MDA: malondialdehyde; MYB: Myeloblastosis; NCED: 9-cisepoxycarotenoid dioxygenase; $\mathrm{NHX}: \mathrm{Na}^{+} / \mathrm{K}^{+}$exchanger; PAL: Phenylalanine-ammonia lyase; PERK: proline extensin like; PP2C: protein phosphatase 2C; POD: Peroxidase; ROS: Reactive oxygen species; SKP: Sphase-associated kinase protein kinases; SOD: Superoxide dismutase; TCA: tricarboxylic; UGE: UDP-glucose 4-epimerase; WAK: S-locus glycoprotein like and wall associated receptor kinase; XTH: Xyloglucan endotransglucosylase.

\section{Declarations}

\section{Ethics approval and consent to participate}

Not applicable

\section{Consent for publication}


Not applicable

\section{Availability of data and materials}

All data generated or analyzed during this study are included in article with its supplementary material. We have deposited our transcriptome data in Sequence Read Archive (SRA)

(http://www.ncbi.nlm.nih.gov/sra/), the accession number for our submission is: PRJNA645038.

\section{Competing interests}

The authors declare that they have no competing interests

\section{Funding}

This work was supported by the National Natural Science Foundation of China (grant no. 31801892) and Natural Science Foundation of Shandong Province, China (grant no. ZR2019PC012).

\section{Authors' contributions}

A.S. and W.W. performed most of the experiments, analyzed most of the data and wrote the article with contributions of all the authors; S.F. provided technical assistance; X.X., Y.Y., X.L., G.W. and H.W. provided experiment assistance; J.F. supervised the experiments. E.A. edited the manuscript. All the authors reviewed the draft.

\section{Acknowledgements}

We thank the novogene company at the WuHan, China, for supporting computational work. We also thank for the fund supporting by the National Natural Science Foundation of China and Natural Science Foundation of Shandong Province.

\section{References}

1. Deinlein U, Stephan AB, Horie T, Luo W, Xu G, Schroeder JI. Plant salt-tolerance mechanisms. Trends Plant Sci. 2014;19(6):371-9.

2. Gupta B, Huang B. Mechanism of salinity tolerance in plants: Physiological, biochemical, and molecular characterization. Int J Genomics. 2014;2014(1):701596.

3. Munns R, Tester M. Mechanisms of salinity tolerance. Annu Rev Plant Biol. 2008;59(1):651-681.

4. Zolla G, Heimer YM, Barak S. Mild salinity stimulates a stress-induced morphogenic response in Arabidopsis thaliana J Exp Bot. 2009;61(1):211-24.

5. Zhu JK. Salt and drought stress signal transduction In plants. Annu Rev Plant Biol. 2002;53(1):247.

6. Carrow, Robert N. Drought resistance aspects of turfgrasses in the southeast: evapotranspiration and crop coefficients. Crop Sci. 1995;35(6):1685. 
7. Harivandi MA, Butler JD, Wu L. Salinity and turfgrass culture. Agronomy. 1992;32:207-29.

8. Marcum KB, Pessarakli M. Salinity tolerance and salt gland excretion efficiency of bermudagrass turf cultivars. Crop Sci. 2006;46(6):2571-74.

9. Peacock CH, Lee DJ, Reynolds WC, Gregg JP, Cooper RJ, Bruneau AH. Effects of salinity on six bermudagrass turf cultivars. Acta Hortic. 2004;661:193-7.

10. Munns R. Genes and salt tolerance: Bringing them together. New Phytol. 2005;167(3):645-63.

11. Fernando VCD, Schroeder DF. Role of ABA in Arabidopsis salt, drought, and desiccation tolerance. In: Abiotic and biotic stress in plants-recent advances and future perspectives. Edited by Shanker AK, Shanker C. Croatia: InTech. 2016.

12. Ji H, Pardo JM, Batelli G, Van Oosten MJ, Bressan RA, Li X. The salt overly sensitive (SOS) pathway: Established and emerging roles. Mol Plant. 2013;6:275-86.

13. Knight $\mathrm{H}$, Trewavas AJ, Knight MR. Calcium signalling in Arabidopsis thaliana responding to drought and salinity. Plant J. 1997;12(5):1067-78.

14. Guo, Y. Molecular characterization of functional domains in the protein kinase SOS2 that is required for plant salt tolerance. Plant Cell. 2001;13(6):1383-400.

15. Mahajan S, Pandey GK Tuteja N. Calcium- and salt-stress signaling in plants: shedding light on SOS pathway. Arch Biochem Biophys. 2008;471,146-58.

16. Mehlmer N, Wurzinger B, Stael S, Hofmann-Rodrigues D, Csaszar E, Pfister B, Bayer R, Teige M. The $\mathrm{Ca}^{2+}$-dependent protein kinase $\mathrm{CPK} 3$ is required for MAPK-independent salt-stress acclimation in Arabidopsis. Plant J. 2010;63(3):484-98.

17. Snedden WA, Fromm H. Calmodulin as a versatile calcium signal transducer in plants. New Phytol. 2001;151(1):35-66.

18. Dietz KJ, Mittler R, Noctor G. Recent progress in understanding the role of reactive oxygen species in plant cell signaling. Plant Physiol. 2016;171(3):1535.

19. Miller G, Suzuki N, Ciftci-Yilmaz S, Mittler R. Reactive oxygen species homeostasis and signalling during drought and salinity stresses. Plant Cell Environ. 2010;33(4):453-67.

20. Noctor G, Reichheld JP, Foyer CH. ROS-related redox regulation and signaling in Semin Cell Dev Biol. 2017;80:3-12.

21. Pang $\mathrm{CH}$, Wang BS: Oxidative stress and salt tolerance in plants. In: Progress in Botany. Edited by Lüttge U, Beyschlag W, Murata J. Berlin, Heidelberg: Springer Berlin Heidelberg; 2008: 231-45.

22. Sah SK, Reddy KR, Li J. Abscisic acid and abiotic stress tolerance in crop plants. Front Plant Sci. 2016;7:571.

23. Yoshida T, Mogami J, Yamaguchi-Shinozaki K. ABA-dependent and ABA-independent signaling in response to osmotic stress in plants. Curr Opin Plant Biol. 2014;21:133-9.

24. Zhao C, Zhang H, Song C, Zhu JK, Shabala S. Mechanisms of plant responses and adaptation to soil salinity. The Innovation. 2020;1(1):100017. 
25. Lata C, Yadav A, Prasad M. Role of plant transcription factors in abiotic stress tolerance. In: Abiotic stress response in plants-physiological, biochemical and genetic perspectives. InTech. 2011.

26. Hanin M, Brini FA, Ebel C, Toda Y, Takeda S, Masmoudi K. Plant dehydrins and stress tolerance. Plant Signal Behav. 2011;6(10):1503-9.

27. Assaha DVM, Akihiro U, Hirofumi S, Rashid AY, Yaish MW. The role of $\mathrm{Na}^{+}$and $\mathrm{K}^{+}$transporters in salt stress adaptation in glycophytes. Front Physiol. 2017;8:509.

28. Brini F, Masmoudi K. Ion Transporters and abiotic stress tolerance in plants. ISRN Mol Biol. 2012;927436.

29. Coudert Y, Périn C, Courtois B, Khong NG, Gantet P. Genetic control of root development in rice, the model cereal. Trends Plant Sci. 2010;15(4):219-26.

30. Hochholdinger F, Tuberosa R. Genetic and genomic dissection of maize root development and architecture. Curr Opin Plant Biol. 2009;12(2):172-7.

31. Jiang Y, Deyholos MK. Comprehensive transcriptional profiling of $\mathrm{NaCl}$-stressed Arabidopsis roots reveals novel classes of responsive genes. BMC Plant Biol. 2006;6:25

32. Liu A, Xiao Z, Li MW, Wong FL, Yung WS, Ku YS, Wang Q, Wang X, Xie M, Yim AK-Y, et al. Transcriptomic reprogramming in soybean seedlings under salt stress. Plant Cell Environ. 2019;42(1):98-114.

33. Postnikova OA, Shao J, Nemchinov LG. Analysis of the alfalfa root transcriptome in response to salinity stress. Plant Cell Physiol. 2013;54(7):1041-55.

34. Song L, Prince S, Valliyodan B, Joshi T, Maldonado dos Santos JV, Wang J, Lin L, Wan J, Wang Y, Xu $D$, et al. Genome-wide transcriptome analysis of soybean primary root under varying water-deficit conditions. BMC Genom. 2016;17(1):57.

35. Hu L, Li H, Chen L, Lou Y, Amombo E, Fu J. RNA-seq for gene identification and transcript profiling in relation to root growth of bermudagrass (Cynodon dactylon) under salinity stress. BMC Genom. 2015;16(1):575.

36. Anuradha U, Tulsi G, Kumar UA, Satisha J, Shinde MP, Kadoo NY, Gupta VS. Global transcriptome analysis of grapevine ( Vitis vinifera) leaves under salt stress reveals differential response at early and late stages of stress in table grape cv. Thompson Seedless. Plant Physiol Bioch. 2018;129:16879.

37. Geng Y, Wu R, Wee CW, Xie F, Wei X, Chan PMY, Tham C, Duan L, Dinneny JR. A Spatio-temporal understanding of growth regulation during the salt stress response in Arabidopsis. Plant Cell. 2013;25(6):2132-54.

38. Lorenzo Ld, Merchan F, Laporte P, Thompson R, Clarke J, Sousa C, Crespi M. A Novel plant leucinerich repeat receptor kinase regulates the response of Medicago truncatula roots to salt stress. Plant Cell. 2009;21(2):668-80.

39. Marshall A, Aalen RB, Audenaert D, Beeckman T, Broadley MR, Butenko MA, Caño-Delgado Al, Vries SD, Dresselhaus T, Felix G, et al. Tackling drought stress: Receptor-like kinases present new 
approaches. Plant Cell. 2012;24(6):2262-78.

40. Ouyang SQ, Liu YF, Liu P, Lei G, Chen SY. Receptor-like kinase OsSIK1 improves drought and salt stress tolerance in rice (Oryza sativa) plants. Plant J. 2010;62(2):316-29.

41. Vaid N, Macovei A, Tuteja N. Knights in action: lectin receptor-like kinases in plant development and stress responses. Mol plant. 2013;6(5):1405-18.

42. Yuriko O, Kazuko YS, Kazuo S, Phan TLS. Sensing the environment: key roles of membrane-localized kinases in plant perception and response to abiotic stress. J Exp Bot. 2013;64(2):445-58.

43. Cao YR, Chen SY, Zhang JS. Ethylene signaling regulates salt stress response. Plant Signal Behav. 2008;3(10):761-3.

44. Kazan K. Diverse roles of jasmonates and ethylene in abiotic stress tolerance. Trends Plant Sci. 2015;20(4):219-29.

45. Feng J, Shi Y, Yang S, Zuo J. 3-Cytokinins. In: Hormone metabolism and signaling in plants. Edited by Li J, Li C, Smith SM: Academic Press; 2017;77-106.

46. Ryu H, Cho YG. Plant hormones in salt stress tolerance. J Plant Biol. 2015;58(3):147-55.

47. Teige M, Scheikl E, Eulgem T, Dóczi R, Ichimura K, Shinozaki K, Dangl JL, Hirt H. The MKK2 pathway mediates cold and salt stress signaling in Arabidopsis. Mol cell. 2004;15(1):141-52.

48. Wang F, Jing W, Zhang W. The mitogen-activated protein kinase cascade MKK1-MPK4 mediates salt signaling in rice. Plant Sci. 2014;227:181-9.

49. Yu L, Nie J, Cao C, Jin Y, Yan M, Wang F, Liu J, Xiao Y, Liang Y, Zhang W. Phosphatidic acid mediates salt stress response by regulation of MPK6 in Arabidopsis thaliana. New phytol. 2010;188(3):762-73.

50. Raja V, Majeed U, Kang H, Andrabi KI, John R. Abiotic stress: Interplay between ROS, hormones and MAPKs. Environ Exp Bot. 2017;137:142-57.

51. Smékalová V, Doskočilová A, Komis G, Šamaj J. Crosstalk between secondary messengers, hormones and MAPK modules during abiotic stress signalling in plants. Biotechnol Adv. 2014;32(1):2-11.

52. Kumar J, Singh S, Singh M, Srivastava PK, Mishra RK, Singh VP, Prasad SM. Transcriptional regulation of salinity stress in plants: A short review. Plant Gene. 2017;11:160-9.

53. Chen H, Lai Z, Shi J, Xiao Y, Chen Z, Xu X. Roles of Arabidopsis WRKY18, WRKY40 and WRKY60 transcription factors in plant responses to abscisic acid and abiotic stress. BMC Plant Biol. 2010;10(1):281.

54. Ding Z, Yan J, Li C, Li G, Wu Y, Zheng SJ. Transcription factor WRKY46 modulates the development of Arabidopsis lateral roots in osmotic/salt stress conditions via regulation of ABA signaling and auxin homeostasis. Plant J. 2015;84(1):56-69..

55. Hu Y, Chen L, Wang H, Zhang L, Wang F, Yu D. Arabidopsis transcription factor WRKY8 functions antagonistically with its interacting partner VQ9 to modulate salinity stress tolerance. Plant $\mathrm{J}$. 2013;74(5):730-745. 
56. Jiang JJ, Ma SH, Ye NH, Jiang M, Cao JS, Zhang JH. WRKY transcription factors in plant responses to stresses. J Integr Plant Biol. 2017;59; 86-101

57. Vanderauwera S, Vandenbroucke K, Inzé A, van de Cotte B, Mühlenbock P, De Rycke R, Naouar N, Van Gaever T, Van Montagu MC, Van Breusegem F. AtWRKY15 perturbation abolishes the mitochondrial stress response that steers osmotic stress tolerance in Proc Natl Acad Sci USA. 2012;109(49):201138.

58. Niu CF, Wei W, Zhou QY, Tian AG, Chen SY. Wheat WRKY genes TaWRKY2 and TaWRKY19 regulate abiotic stress tolerance in transgenic Arabidopsis Plant Cell Environ. 2012;35(6):1156-70.

59. Tao Z, Kou Y, Liu H, Li X, Xiao J, Wang S. OsWRKY45 alleles play different roles in abscisic acid signalling and salt stress tolerance but similar roles in drought and cold tolerance in rice. $J$ Exp Bot. 2011; 62(14):p.4863-74.

60. Shkolnik-Inbar D, Bar-Zvi D. ABI4 mediates abscisic acid and cytokinin inhibition of lateral root formation by reducing polar auxin transport in Arabidopsis. Plant Cell. 2011;22(5):3560-73.

61. Gilmour SJ, Zarka DG, Stockinger EJ, Salazar MP, Houghton JM, Thomashow MF. Low temperature regulation of the Arabidopsis $\mathrm{CBF}$ family of AP2 transcriptional activators as an early step in coldinduced COR gene expression. Plant J. 2001;16(4):433-42.

62. Ohmetakagi M, Shinshi $\mathrm{H}$. Ethylene-inducible DNA-binding proteins that interact with an ethyleneresponsive element. Plant Cell. 1995;7(2):173-82.

63. Jiang Y, Yang B, Deyholos MK. Functional characterization of the Arabidopsis bHLH92 transcription factor in abiotic stress. Mol Genet Genomics. 2009;282(5):503-16.

64. Shani E, Salehin M, Zhang Y, Sanchez SE, Doherty C, Wang R, Mangado CC, Song L, Tal I, Pisanty O, et al. Plant stress tolerance requires auxin-sensitive Aux/IAA transcriptional repressors. Curr Biol. 2017;27(3):437-44.

65. Hanin M, Ebel C, Ngom M, Laplaze L, Masmoudi K. New insights on plant salt tolerance mechanisms and their potential use for breeding. Front Plant Sci. 2016;7:1787.

66. Li P, Li YJ, Zhang FJ, Zhang GZ, Jiang XY, Yu HM, Hou BK. The Arabidopsis UDP-glycosyltransferases UGT79B2 and 79B3, contribute to cold, salt and drought stress tolerance via modulating anthocyanin accumulation. Plant J. 2016;89(1):89-103.

67. Gill SS, Tuteja N. Reactive oxygen species and antioxidant machinery in abiotic stress tolerance in crop plants. Plant Physiol Biochem. 2010;48(12):909-30.

68. Mittler R, Vanderauwera S, Gollery M, Van Breusegem F. Reactive oxygen gene network of plants. Trends Plant Sci. 2004;9(10):490-8.

69. Winkel-Shirley B. Biosynthesis of flavonoids and effects of stress. Curr Opin Plant Biol. 2002;5(3):218-23.

70. Feng W, Kita D, Peaucelle A, Cartwright HN, Doan V, Duan Q, Liu MC, Maman J, Steinhorst L, SchmitzThom I, et al. The FERONIA receptor kinase maintains cell-wall integrity during salt stress through $\mathrm{Ca}^{2+}$ Curr. Biol. 2018;28(5):666-75. 
71. Zhao C, Zayed O, Yu Z, Jiang W, Zhu JK. Leucine-rich repeat extensin proteins regulate plant salt tolerance in Arabidopsis. P Natl Acad Sci USA. 2018;115(51):201816991.

72. Coutinho PM, Henrissat B. Carbohydrate-active Enzymes: An integrated database approach. Recent Advances in Carbohydrate Bioengineering. 1999; 246:3-12.

73. Lee Y, Choi D, Kende H. Expansins: ever-expanding numbers and functions. Curr Opin Plant Biol. 2001;4(6):527-32.

74. Jones L, McQueen-Mason S. A role for expansins in dehydration and rehydration of the resurrection plant Craterostigma plantagineum. FEBS Lett. 2004;559(1-3):61-5.

75. Vissenberg K, Oyama M, Osato Y, Yokoyama R, Verbelen JP, Nishitani K. Differential expression of AtXTH17, AtXTH18, AtXTH19 and AtXTH20 genes in Arabidopsis Physiological roles in specification in cell wall construction. Plant Cell Physiol. 2005;46(1):192-200.

76. Zhao C, Zayed O, Zeng F, Liu C, Zhang L, Zhu P, Hsu CC, Tuncil YE, Tao WA, Carpita NC, et al. Arabinose biosynthesis is critical for salt stress tolerance in Arabidopsis. New Phytol. 2019;224(1):274-90.

77. Ellis M, Egelund J, Schultz CJ, Bacic A. Arabinogalactan-proteins: Key regulators at the cell surface? Plant Physiol. 2010; 153(2):403-19.

78. Majewska-Sawka A, Nothnagel EA. The multiple roles of arabinogalactan proteins in plant development. Plant Physiol. 2000;122(1):3-10.

79. Shi H, Kim Y, Guo Y, Stevenson B, Zhu JK. The Arabidopsis SOS5 locus encodes a putative cell surface adhesion protein and is required for normal cell expansion. Plant Cell. 2003;15(1):19-32.

80. Sui N, Wang Y, Liu S, Yang Z, Wang F, Wan S. Transcriptomic and physiological evidence for the relationship between unsaturated fatty acid and salt stress in peanut. Front Plant Sci. 2018;9(7).

81. Sun YL, Li F, Su N, Sun XL, Zhao SJ, Meng QW. The increase in unsaturation of fatty acids of phosphatidylglycerol in thylakoid membrane enhanced salt tolerance in tomato. Photosynthetica. 2010;48(3):400-8.

82. Zhang JT, Zhu JQ, Zhu Q, Liu H, Gao XS, Zhang HX. Fatty acid desaturase-6 (Fad6) is required for salt tolerance in Arabidopsis thaliana. Biochem Biophys Res Commun. 2009;390(3):469-74.

83. Akula R, Ravishankar GA. Influence of abiotic stress signals on secondary metabolites in plants. Plant Signal Behav. 2011;6(11):1720-31.

84. Thakur M, Bhattacharya S, Khosla PK, Puri S. Improving production of plant secondary metabolites through biotic and abiotic elicitation. J Appl Res Med Aroma. 2019;12:1-12.

85. Liang M, Haroldsen V, Cai $X$, Wu Y. Expression of a putative laccase gene, $Z m L A C 1$, in maize primary roots under stress. Plant Cell Environ. 2006;29(5):746-53.

86. Pourcel L, Routaboul JM, Cheynier V, Lepiniec L, Debeaujon I. Flavonoid oxidation in plants: from biochemical properties to physiological functions. Trends Plant Sci. 2007;12(1):29-36.

87. Ranocha P. Laccase Down-regulation causes alterations in phenolic metabolism and cell wall structure in poplar. Plant Physiol. 2002;129(1):145-55. 
88. Ndimba BK, Chivasa S, Simon WJ, Slabas AR. Identification of Arabidopsis salt and osmotic stress responsive proteins using two-dimensional difference gel electrophoresis and mass spectrometry. Proteomics. 2005;5(16): 4185-96.

89. Smalle J, Vierstra RD. The ubiquitin $26 \mathrm{~S}$ proteasome proteolytic pathway. Annu Rev Plant Biol. 2004;55:555-90.

90. Kawaguchi R, Girke T, Bray EA, Bailey-Serres J. Differential mRNA and dehydration stress conditions in Arabidopsis thaliana .Plant J. 2004;38:823-9.

91. Moller IM: Plant mitochondria and oxidative stress: Electron transport, NADPH turnover, and metabolism of reactive oxygen species. Annu Rev Plant Phys. 2001;52:561-91.

92. Thimm O, O B, Gibon Y, Nagel A, Meyer S, Krüger P, Selbig J, Müller LA, Rhee SY, Stitt M. MAPMAN: a user-driven tool to display genomics data sets onto diagrams of metabolic pathways and other biological processes. Plant J. 2004;37(6):914.

93. Ernst J, Bar-Joseph Z. STEM: a tool for the analysis of short time series gene expression data. BMC Bioinform. 2006;7(1):1-11.

94. Langfelder P, Horvath S. WGCNA: an R package for weighted correlation network analysis. BMC Bioinform. 2008;9:559.

\section{Figures}



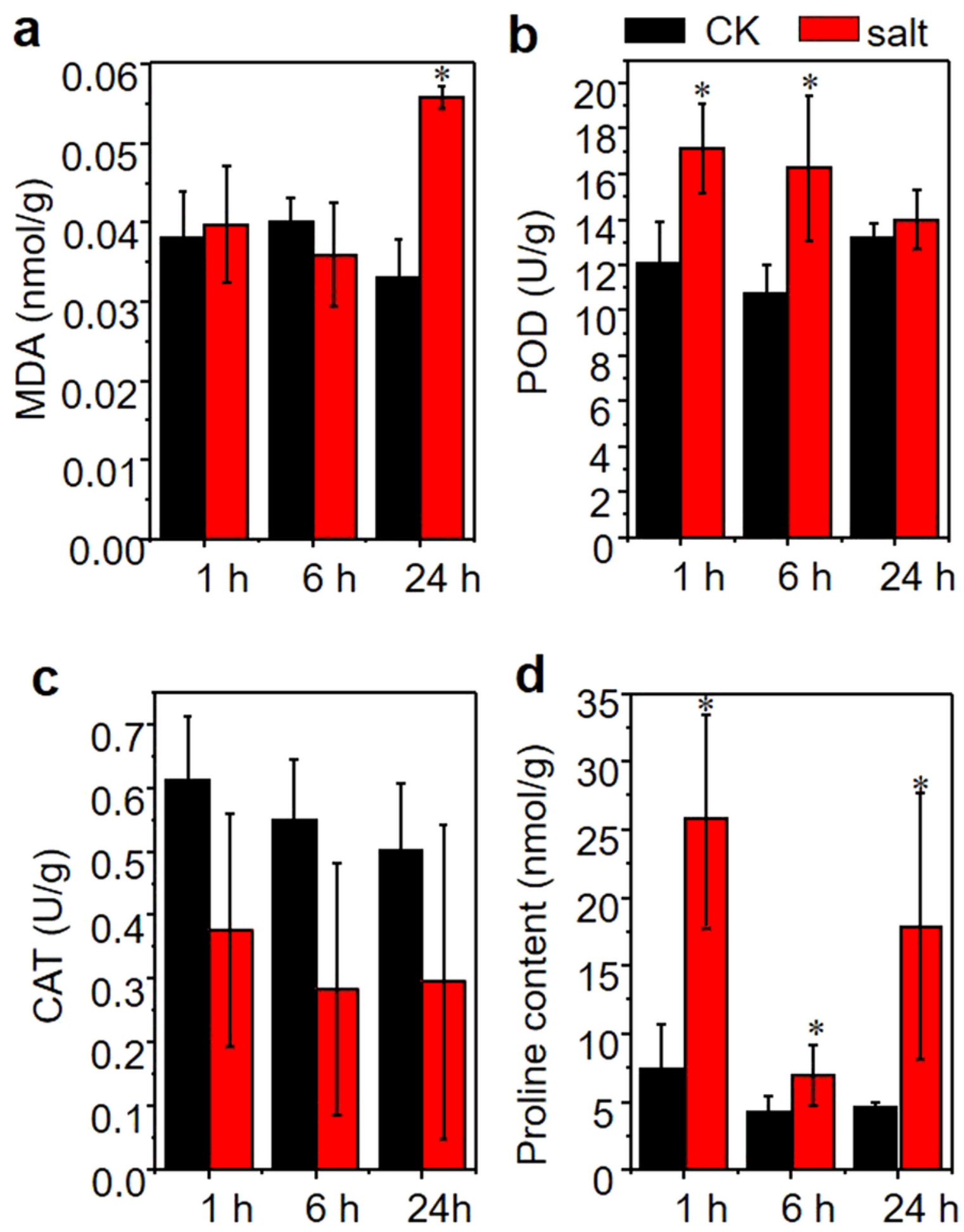

Figure 1

Physiological indicators of bermudagrass roots grown under control and salt conditions. The uniform stolons of bermudagrass were planted in solid in one month, and the seedlings mowed to the same height were then transferred into $\mathrm{CK}(0 \mathrm{mM} \mathrm{NaCl})$ and salt stress $(100 \mathrm{mM} \mathrm{NaCl})$ conditions for $1 \mathrm{~h}, 6 \mathrm{~h}$ or $24 \mathrm{~h}$ in a hydroponic culture. After being grown for 10 days, the MDA content (a), POD activity (b), CAT activity (c) and proline content (d) were measured. Data are means \pm SD of three independent 
experiments; * indicate statistically significant difference between control and salt at $\mathrm{P}<0.05$ by Student's t-test stress under certain time point.

a

\section{Up-regulated}

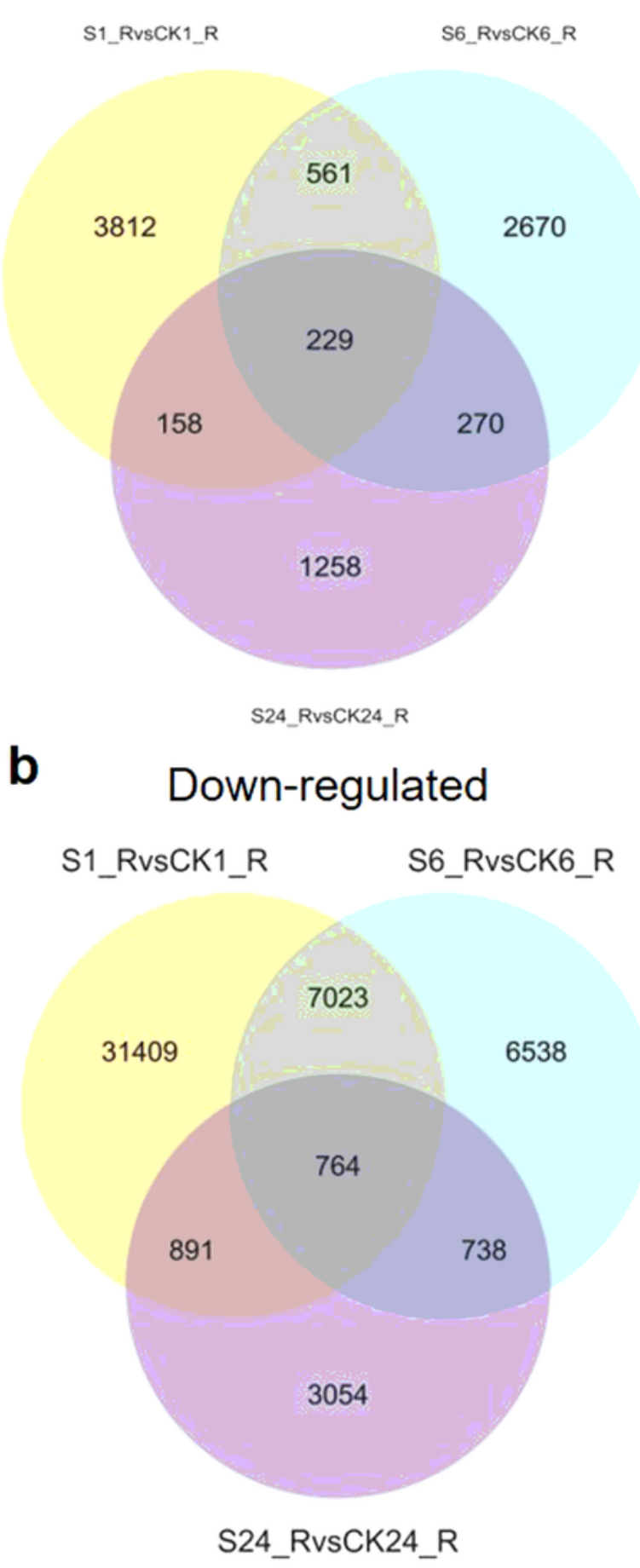

C
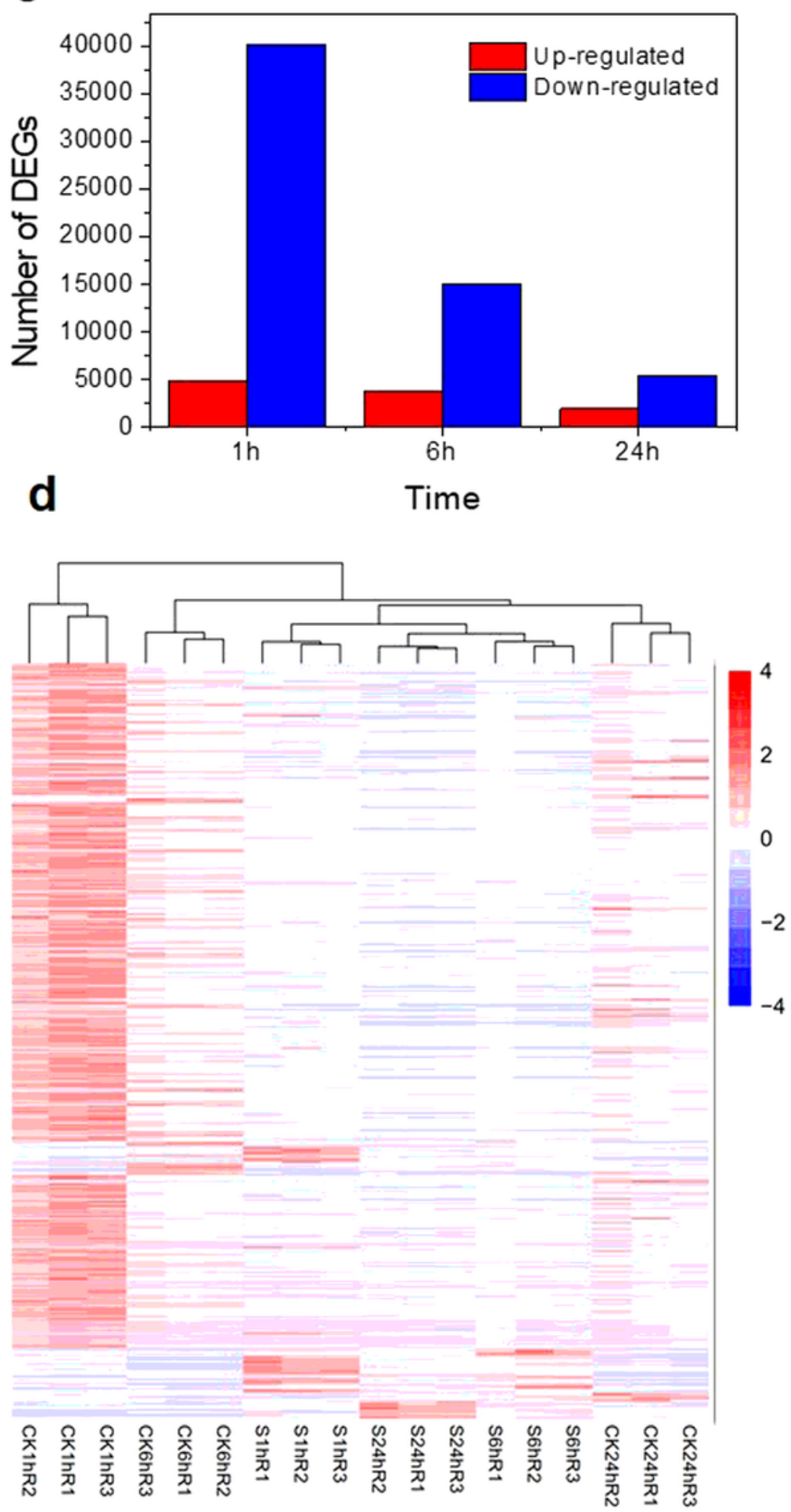

Figure 2

Summary of different expression genes after exposed to salt for different time period. Venn diagram showing the overlap of up-regulated genes (a) and down-regulated genes (b) at various time points ( $1 \mathrm{~h}, 6$ h, $24 \mathrm{~h}$ ). The numbers of DEGs exclusively expressed in one sample are shown in each circle. The 
numbers of DEGs with a common tendency of expression changes between the two treatments are shown in the overlapping regions. (S1_R_salt, $\mathrm{NaCl}$ treated for $1 \mathrm{~h}$; $\mathrm{CK} 1 \_C o n t r o l$, without $\mathrm{NaCl}$ treated for 1 h; S6_R_salt, NaCl treated for 6h; CK6_Control, without NaCl treated for 6 h; S24_R_salt, NaCl treated for $24 \mathrm{~h}$; CK1_Control, without $\mathrm{NaCl}$ treated for $24 \mathrm{~h}$ ). c The number DEGs under different time point. d Heatmap of the relative expression levels of of DEGs under different time point.
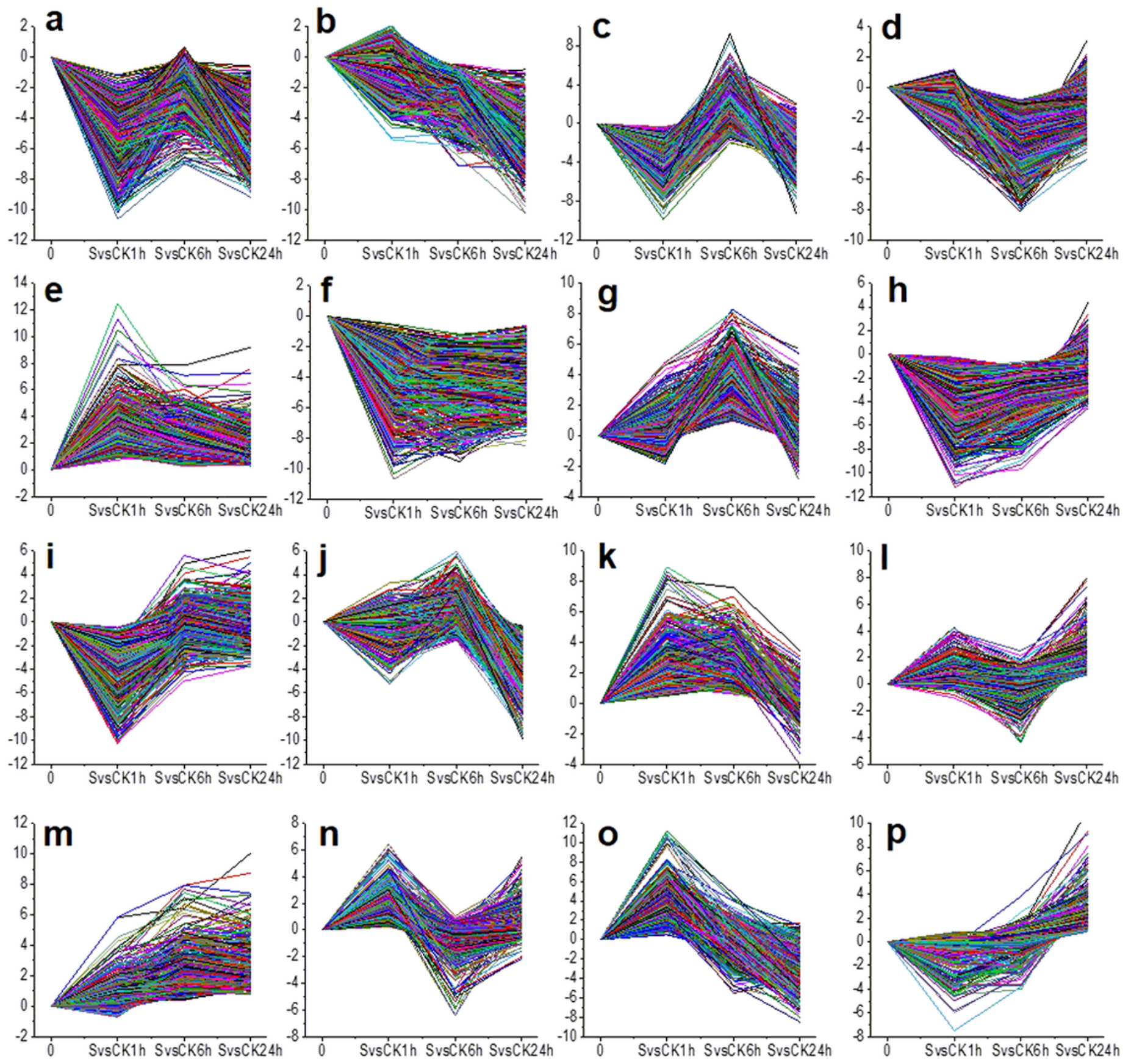

\section{Figure 3}

Different expression genes grouped according to temporal expression profiles using STEM software. DEGs was mainly divided into 16 distinct temporal profiles. Each of the profiles (a-p) is represented as a 

point.

a

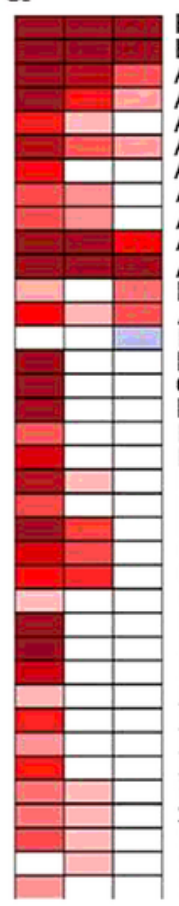

Hormone metabolism(17)

Hormone metabolism.ABA(17.1)

ABA synthesis(17.1.1)

ABA synthesis 17.1 .1 .116

ABA synthesis 17.1 .1 .10$)$

ABA degradation $(17.1 .12$

$A B A$ synthesis(17.1.1.11)

ABA degradation $(17.1 .1,2.1)$

ABA induced-regulated-responsi

ABA induced-regulated-responsive-activiated(17.1.3)

Hormone metabolism.auxin(17.2)

Auxin induced-regulated-responsive-activated(17.2.3)

Brassinosteroid.synthesis-degradation(17.3.1.2)

Hormone metabolism.CTK(1).4)

CTK synthesis-degradation (17.4.1)

Hormone metabolism.ETH (17.5)

ETH.synthesis-degradation (17.5.1)

ETH.synthesis-degradation (17.5.

ETH.induced-regulated-respon

Hormone metabolism.GA (17.6)

GA.synthesis-degradation (17.6.1)

GA.signal transduction(17.6.2)

Hormone metabolism.JA (17.7)

JA.synthesis-degradation (17.7.1)

JA.synthesis-degradation 17.7 .1 .4

JA.synthesis-degradation (17.7.1.10)

Hormone metabolism.SA(17.8)

SA. Synthesis-degradation(17.8.1

SA. Synthesis-degradation(17.8.1.1)

SA. Synthesis-degradation (17.8.1.1.4)

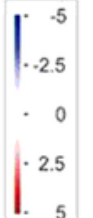

SA. Synthesis-degradation(17.8.1.1.7)

C

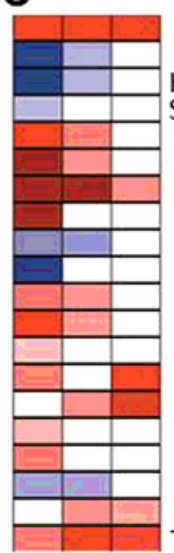

Transport(34)

Transport.P-and v-ATPase(34.1)

$\mathrm{H}+$ transporting two-sector ATPase(34.1.1)

Subunit C (34.1.2)

Transport.Sugars (34.2)

Transport.Sugars .sucrose(34.2.1)

Transport.amino acids (34.3)

Transport.nitrate(34.4)

Transporters at envelope membrane(34.8)

Transporters at mitochondrial membrane (34.9)

Transport.metal(34.12)

Transport.potassium(34.15)

Transport.unspecified anions (34.18)

Transport.major intrinsic proteins (34.19)

Major intrinsic proteins.PIP (34.19.1)

Major intrinsic proteins.NIP (34.19.3)

Transport.calcium(34.21)

$\mathrm{H}+$ transpoting pyrophosphatase $(34.30)$

Transport.membrane system unknown (34.98)

Transport.misc(34.99)

e

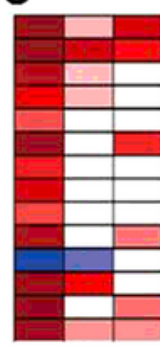

Stress(20)

Stress.biotic(20.1)

Respiratory burst(20.1.1)

Stress.biotic.signalling (20.1.3)

Signaling.MLO-like(20.1.3.1)

Stress.biotic.PR-proteins (20.1.7)

Proteinase inhibitor(20.1.7.6

Typsin inhibitor 20.1 .7 .6 .1

PR-proteins.NPR(20.1

Stress.abiotic (20.2)

Stress.abiotic.heat(20.2.1)

Drought/salt(20.2.

Touch/wounding(20.2.4)

Stress.unspeicified (20.2.99) b

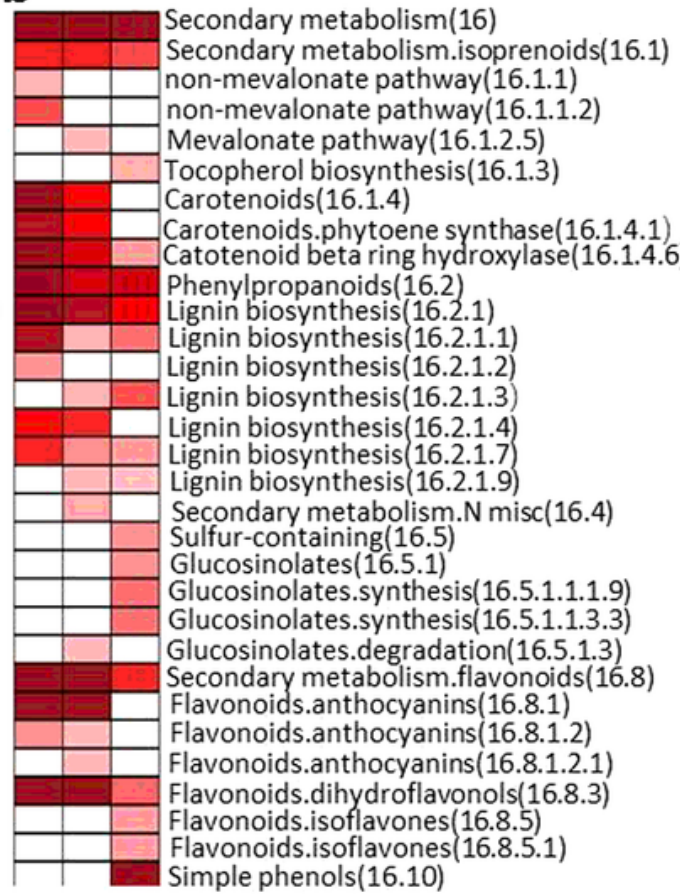

d

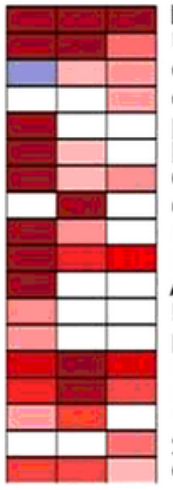

$\operatorname{Misc}(26)$

UDP gludosyl and glucoronyl transferases(26.2)

Gluco-,galacto-and mannosidases(26.3)

Gluco-,galacto-and mannosidases(26.3.3)

beta 1,3 glucan hydrolases $(26.4)$

beta 1,3 glucan hydrolases (26.4.1)

Glutathione S transferases(26.9)

Cytochrome P450(26.10)

Peroxidases(26.12)

Acid and other phosphatases(26.13)

Myrosinases-lectin-jacalin(26.16

pecion methylesterase inhibitor family (26.18)

Plastocyanin-like(26.19)

Protease inhibitor/lipid transfer protein(26.21)

Short chain dehydrogenase/reductase(26.22)

Sulfotransferase(26.25)

GDSL-motif lipase(26.28)

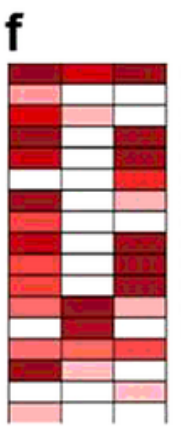

Cell Wall(10)

Precursor synthesis.UGE(10.1.2)

Precursor synthesis. MUR4(10.1.9)

Cellu ose synthesis (10.2)

Ce u ose syntpase(10.2.1)

Hemicellulose synthesis(10.3)

Glycuronoxylan (10.3.2)

Ce wall proteins 10.5$)(10.5 .1)$

Cell wall proteins.AGPs. AGP $(10.5 .1 .1)$

Cell wall degradation(10.6)

Pectate lyases and polygalacturonases(10.6.3)

Mannan-xylose-arabinose-fucose(10.6.2)

Cell wall modification (10.7)

Pectin esterases(10.8.1)

Figure 4

PageMan display of coordinated changes of selected gene categories activated by salt. a Hormone metabolism, b Secondary metabolism, c Transport, d Misc, e Stress, f Cell wall. The log2 Fold change of SvsCK1h (left column), SvsCK6h (middle column) and SvsCK24h (right column) were subjected to over- 

depletion of up-regulated genes. The complete analysis and its display are provided in Supplemental Figure S6 and Table S3.

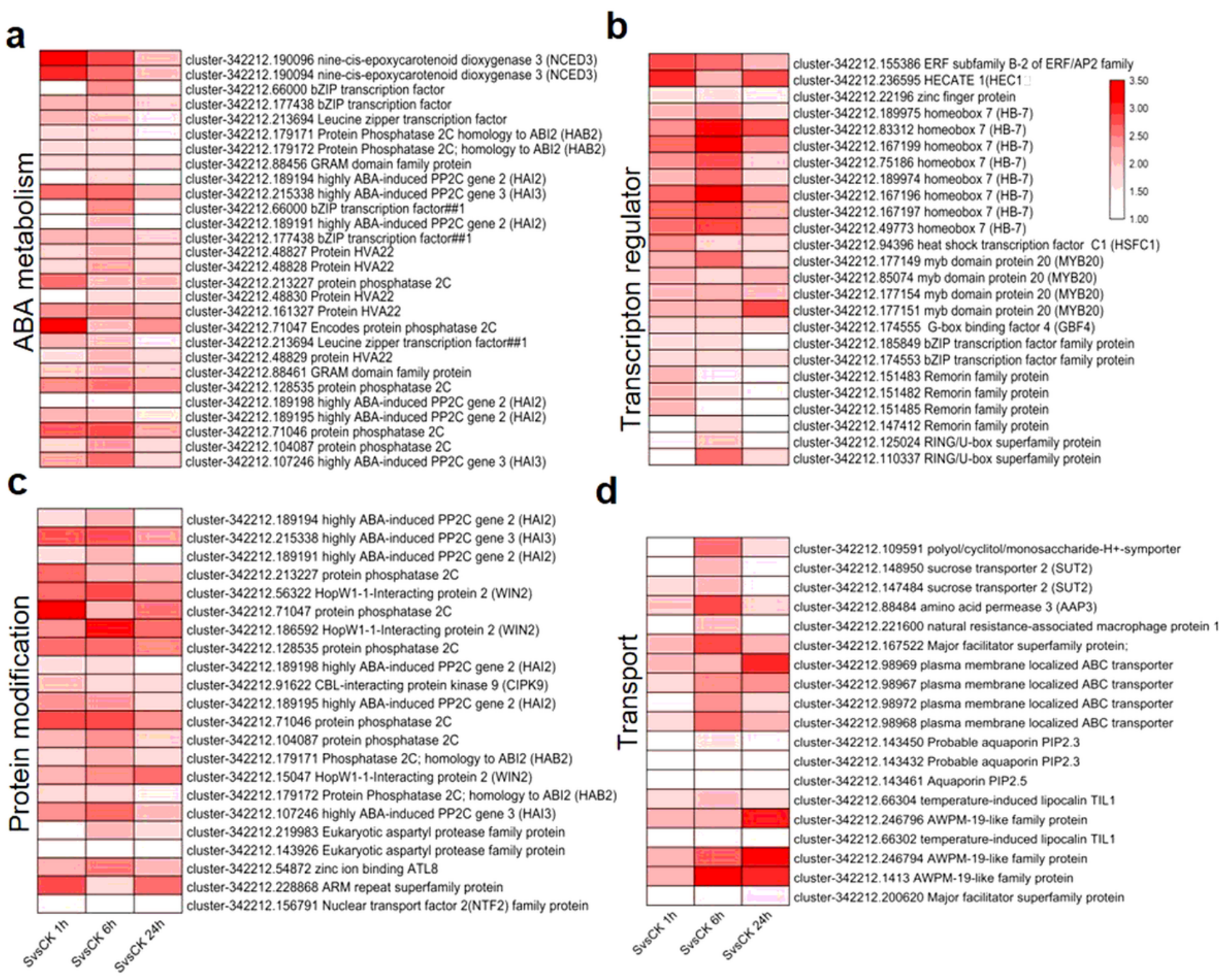

\section{Figure 5}

Expression of selected co-upregulated genes after salt stress displayed by Heatmap diagram. a Members of ABA metabolism related gene. b Transcription regulators. c Protein modification related genes. $d$ Transporters. SvsCK1h (left column), SvsCK6h (middle column) and SvsCK24h (right column). 


\section{a}
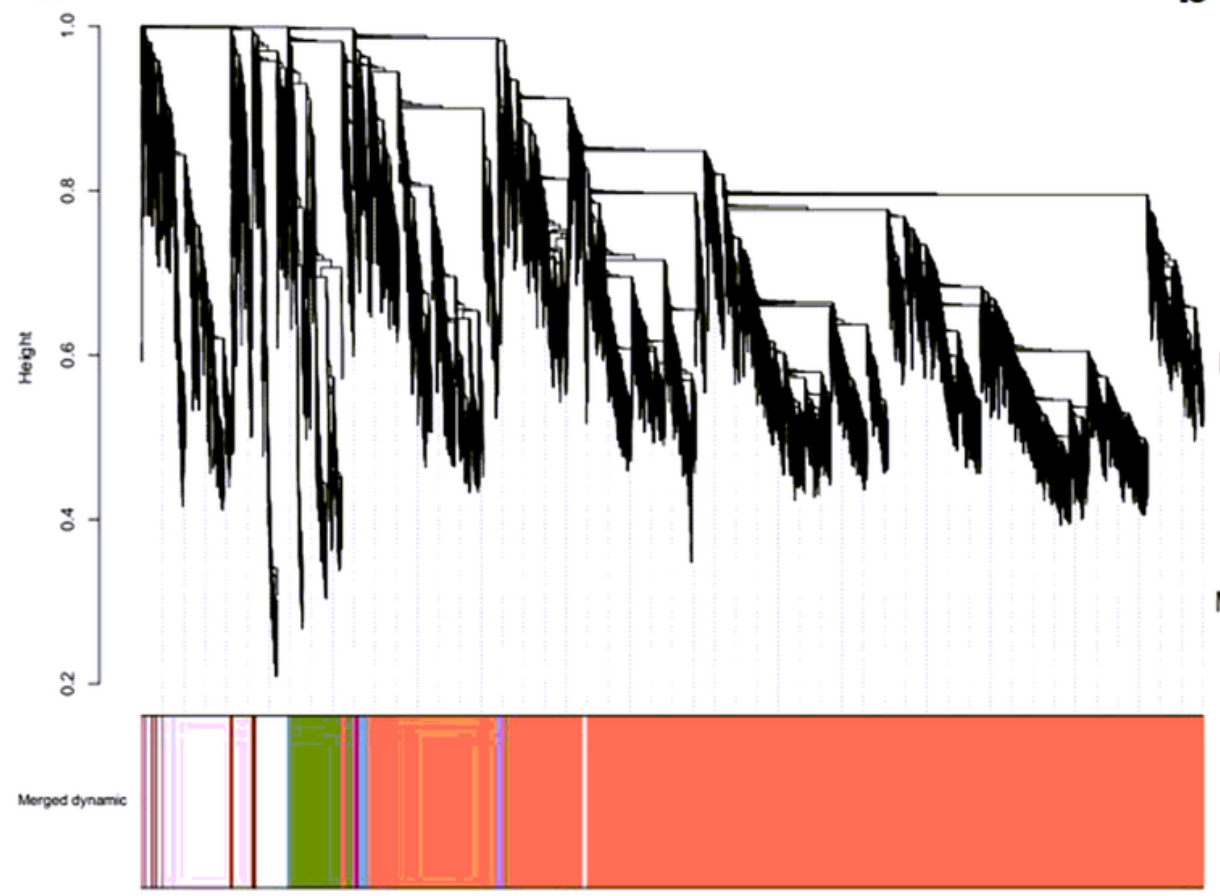

b

\section{Module-Sample Relationships}

C
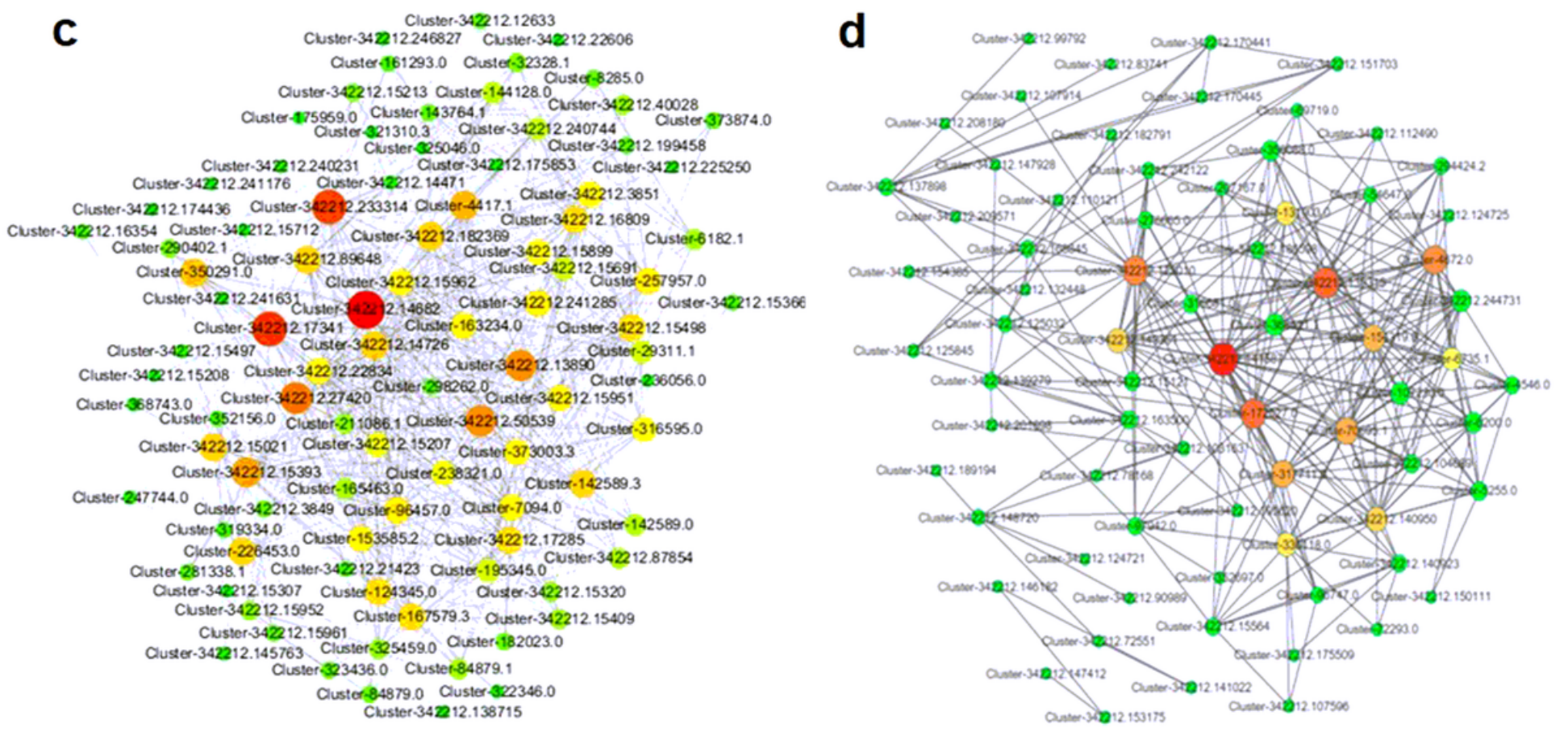

MElavenderblush1

MEmediumpurple1

MElavenderblush2

MEpink4

MEbrown4

MEhoneydew

MEantiquewhite2

MEfirebrick4

MEgrey

$e^{x^{\circ}} \quad 8^{0^{\circ}} 9^{0^{\circ}}$
MEdarkolivegreen4

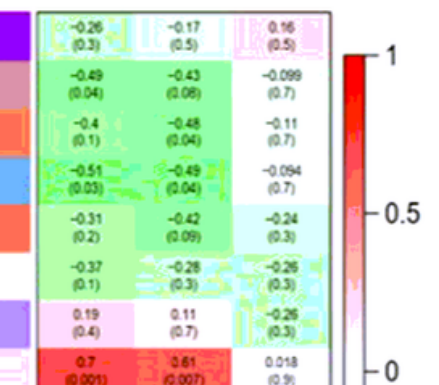

(i)

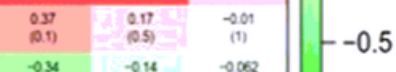

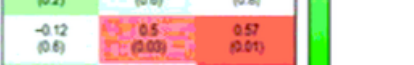

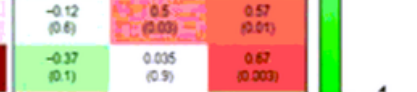

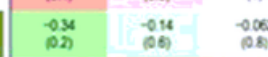


coded by correlation according to the color legend. The right panel is a color scale for module trait correlation from -1 to 1 . Visualization of key co-expression network lavenderblush2 module (c) and brown4 (d) module by Cytoscape. Key hub genes identified by WGCNA and transcription factors indicated by larger and red circles.
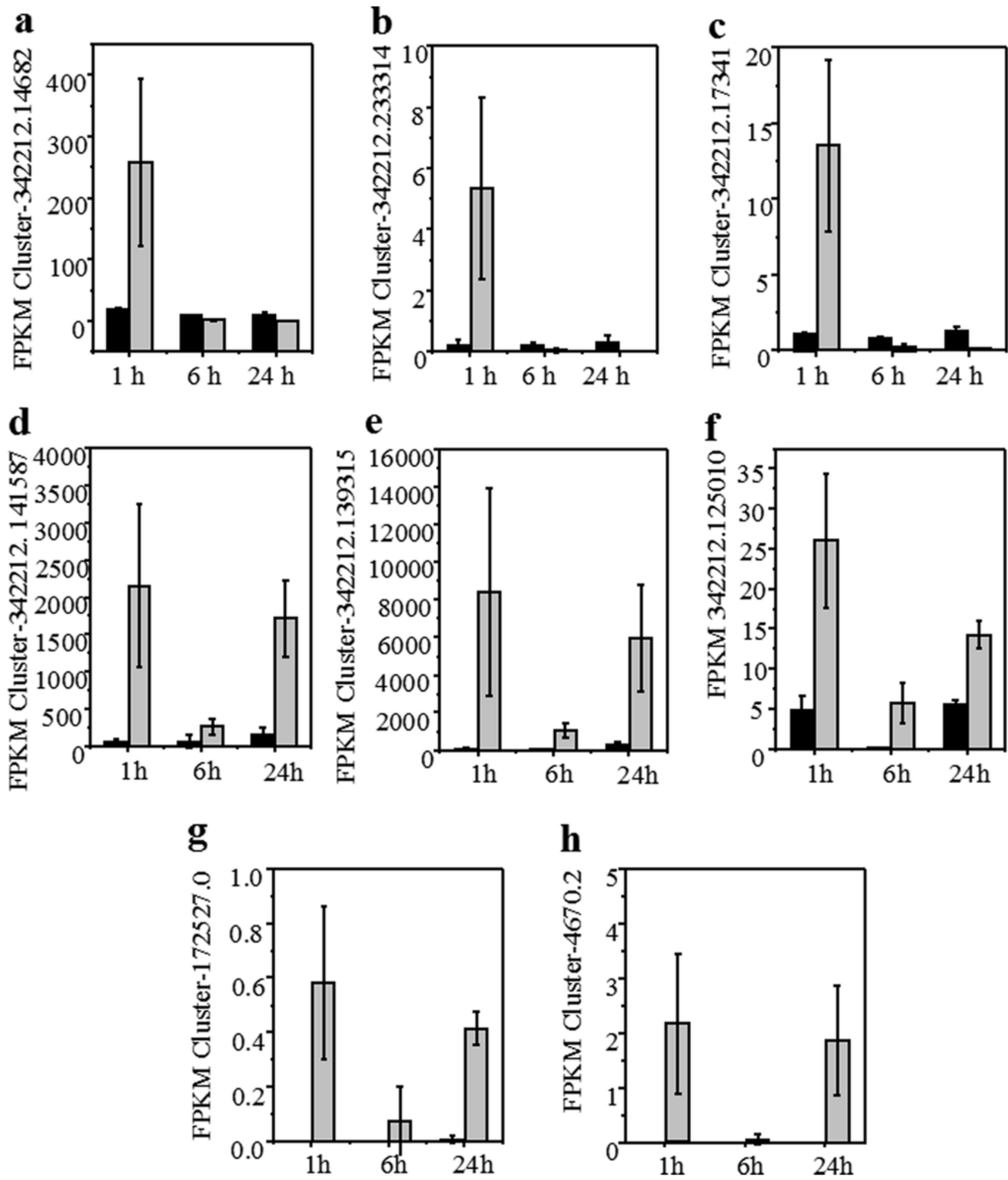

Figure 7 
Transcript abundance of hub genes in the lavenderblush2 and brown4 modules. a-c, Hub genes from lavenderblush2 module. $d-h$, Hub genes from brown4 module. Transcript abundance are presented as the mean $\pm S E$ of FPKM values, $n=3$ at each time point.

\section{Supplementary Files}

This is a list of supplementary files associated with this preprint. Click to download.

- TableS1.xIsx

- TableS2.xIsx

- TableS3.xIsx

- TableS4.xlsx

- TableS5.xlsx

- TableS6.xIsx

- TableS7.xlsx

- TableS8.xIsx

- Fig.S1.tif

- Fig.S2.tif

- Fig.S3.tif

- Fig.S4.tif

- Fig.S5.tif

- Fig.S6.TIF

- Fig.S7.tif

- Fig.S8.tif 